\title{
Sub-Bandgap Luminescence from Doped Polycrystalline and Amorphous Silicon Films and Its Application to Understanding Passivating-Contact Solar Cells
}

\author{
Hieu T. Nguyen, ${ }^{* \dagger \odot}$ Anyao Liu, ${ }^{\dagger}$ Di Yan, ${ }^{\dagger}$ Harvey Guthrey, ${ }^{\ddagger}$ Thien N. Truong, ${ }^{\dagger}$ \\ Mike Tebyetekerwa, ${ }^{\dagger}$ Zi Ziyuan Li, ${ }^{\S}{ }^{\circledR}$ Zhuofeng Li, ${ }^{\dagger}$ Mowafak M. Al-Jassim, ${ }^{\dagger}$ Andres Cuevas, ${ }^{\dagger}$ \\ and Daniel Macdonald ${ }^{\dagger}$ \\ ${ }^{\dagger}$ Research School of Engineering, The Australian National University, Canberra, ACT 2601, Australia \\ ${ }^{\ddagger}$ National Renewable Energy Laboratory, Golden, Colorado 80401, United States \\ ${ }^{\S}$ Department of Electronic Materials Engineering, The Australian National University, Canberra, ACT 2601, Australia
}

ABSTRACT: We report luminescence phenomena from doped polycrystalline silicon (poly-Si) films and their applications to study carrier transport properties in passivating-contact solar cells. Low-temperature luminescence spectra emitted from doped poly-Si layers are found to be very broad and stretched from the crystalline silicon (c-Si) luminescence peak to significantly lower energies. This suggests that these layers contain radiative defect levels whose energies are continuously distributed from the band edges to deep levels in the poly-Si bandgap. Moreover, photoinduced carriers inside poly-Si layers are found to be completely blocked by an ultrathin $\mathrm{SiO}_{x}$ interlayer $(\sim 1.3 \mathrm{~nm})$. This demonstrates that there is no free-carrier coupling from poly-Si layers in practical

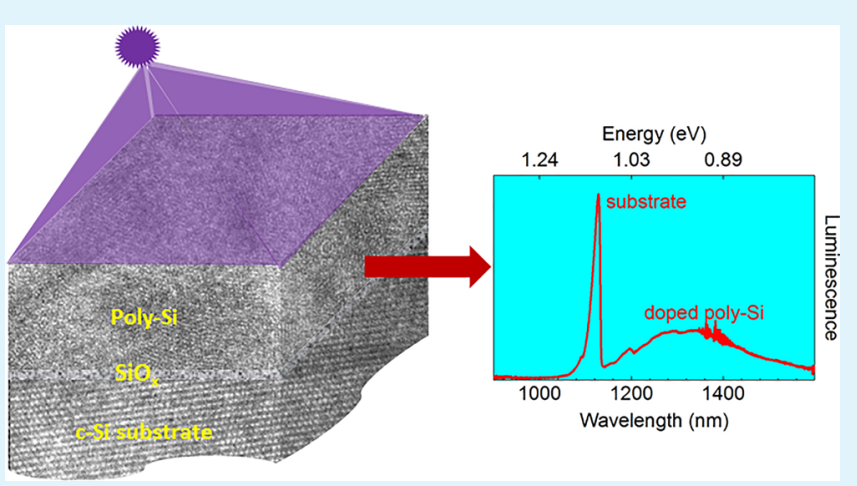
passivating-contact solar cells. Finally, we demonstrate that the same principle can be applied to study carrier transport properties in hydrogenated amorphous silicon films.

KEYWORDS: luminescence, polycrystalline silicon, amorphous silicon, passivating contacts, solar cells, sub-bandgap

\section{INTRODUCTION}

Luminescence spectroscopy has been demonstrated to be a powerful technique to investigate optoelectronic properties of various structures in crystalline silicon (c-Si) solar cells. Bandto-band photoluminescence (PL) spectra from c-Si have been used to extract fundamental parameters of the material such as the band-to-band absorption coefficient, ${ }^{1-4}$ the radiative recombination coefficient, ${ }^{3,5,6}$ temperature $^{7}$ and doping dependencies $^{8,9}$ of the c-Si bandgap, dopant concentrations, $^{10,11}$ diffusion lengths of minority carriers in $\mathrm{c}-\mathrm{Si}$ wafers ${ }^{12,13}$ and bricks, ${ }^{14}$ as well as the light trapping capability of various plasmonic structures. ${ }^{15}$ Moreover, sub-bandgap PL spectra have been employed to investigate the nature of various defects in c-Si wafers, such as dislocations, ${ }^{16-20}$ metal precipitates, ${ }^{21}$ oxygen precipitates, $^{22-25}$ or laser-induced defects. $^{26,27}$ In addition, some deposited thin films acting as both surface passivation and antireflection coating layers have also been demonstrated to emit strong PL signals at low temperatures. Their PL spectral shapes, peak locations, and intensities are very sensitive to the film composition and fabrication conditions, thus allowing the extraction of various film properties such as refractive indices and thicknesses. ${ }^{28-31}$

An attractive approach for high-efficiency c-Si solar cells is to employ the so-called passivating contacts. ${ }^{32-36}$ They consist of thin layers placed between a c-Si absorber and two metal electrodes and function as both surface passivation layers and selective conductors to extract free electrons or holes from the absorber. This class of solar cell structures has been demonstrated to give light-to-electricity conversion efficiencies of $>25 \%$ employing hydrogenated amorphous silicon (a-Si:H) heterojunction contacts ${ }^{37-39}$ or an ultrathin $\mathrm{SiO}_{x}$ layer capped with doped polycrystalline silicon (poly-Si) as a passivating contact. $^{40-42}$ A drawback of a-Si:H and poly-Si is that they strongly absorb light in the ultraviolet to blue region, resulting in relatively large absorption losses if placed on the front side of a solar cell. However, from a different perspective, as these layers absorb some light, they can also be expected to luminesce. Moreover, changes in the film optoelectronic properties and structure could lead to characteristic signatures in their PL spectra. There is, therefore, a unique opportunity to probe the optoelectronic properties of these films in a nondestructive and contactless manner by capturing and interpreting their PL spectra.

Received: September 14, 2018

Accepted: October 16, 2018

Published: October 16, 2018 

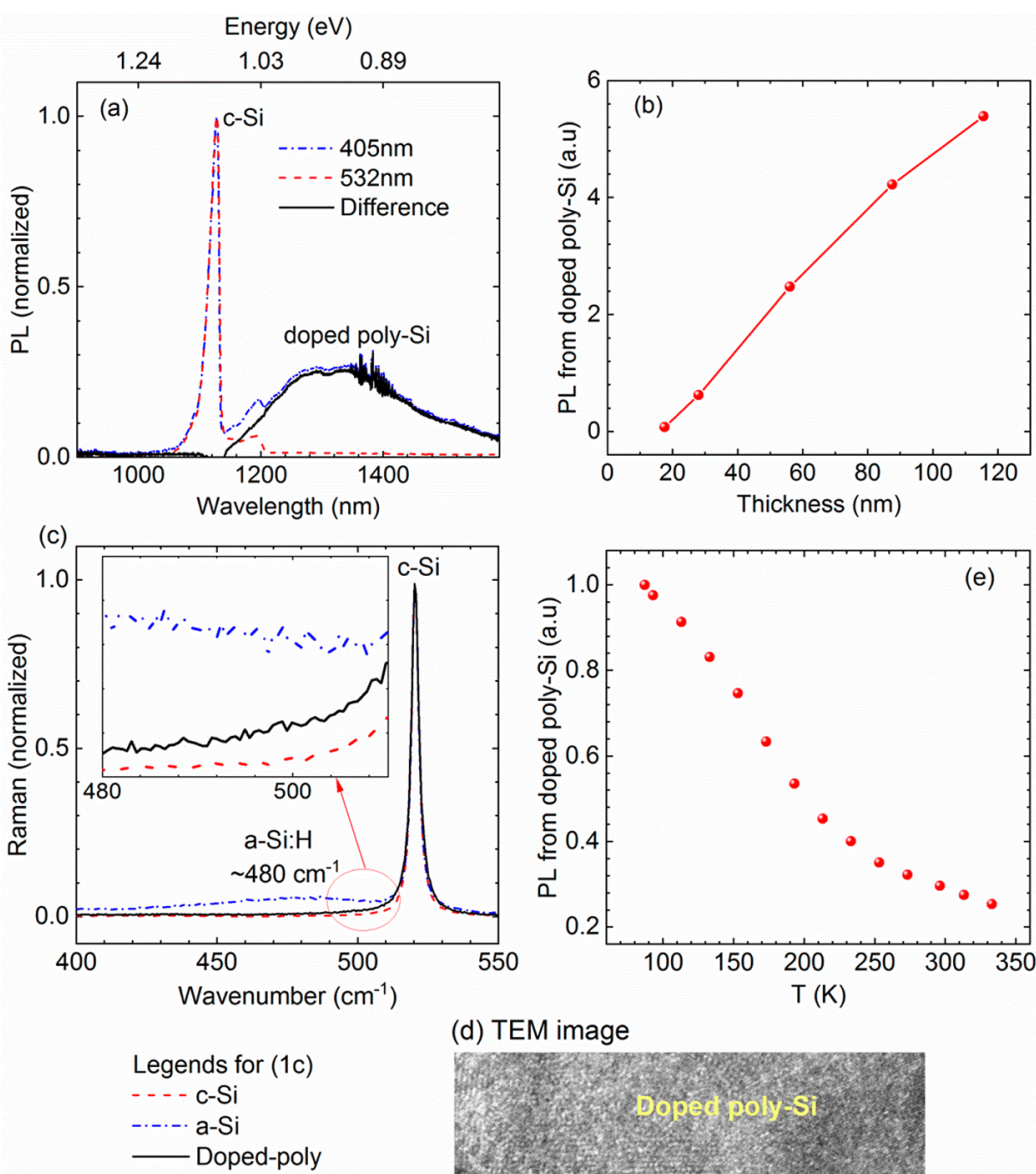

(d) TEM image

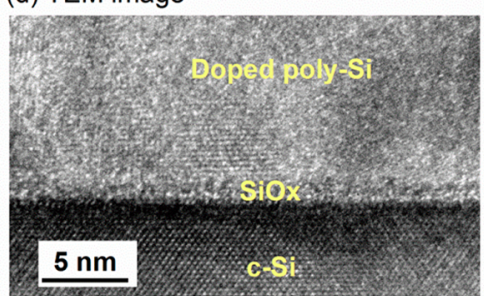

Figure 1. (a) PL spectra from a doped poly-Si structure $\left(\mathrm{n}^{+}\right.$poly/1.3 nm oxide/c-Si) with 532 and $405 \mathrm{~nm}$ excitation wavelengths and the difference spectrum between the two spectra, at $80 \mathrm{~K}$. (b) Integrated PL signal (1250-1550 nm) from the doped poly-Si layer versus doped poly-Si thickness, at $80 \mathrm{~K}$. (c) Raman spectra from a-Si:H and doped poly-Si films. (d) High-resolution TEM image of the $\mathrm{n}^{+}$poly/oxide/c-Si interface shows amorphous silicon clusters in the poly-Si film. (e) Temperature dependence of integrated PL intensities from doped poly-Si films. $\lambda_{\text {exc }}=405$ and $532 \mathrm{~nm}$ for PL and Raman measurements, respectively.

In this study, we report photoluminescence phenomena from phosphorus-doped poly-Si and a-Si:H films and employ them to investigate transport properties of photoinduced carriers generated within the films. First, we examine luminescence signals from a c-Si wafer capped with a $\mathrm{SiO}_{x} /$ doped poly-Si stack and demonstrate that the poly-Si film emits a broad PL peak, which can be associated with the presence of defect levels within the energy bandgap of the poly-Si. We then investigate the intensity dependence of such a broad peak on various parameters, including poly-Si and $\mathrm{SiO}_{x}$ film thickness, temperature, and laser excitation power. The results provide insight about free-carrier transport between the deposited film and the wafer. After that, we extend the technique to investigate free-carrier transport in a-Si:H films using the same principles.

\section{EXPERIMENTAL DETAILS}

The investigated samples are float-zone (FZ) $1-5 \Omega \mathrm{cm}$ p-type $\mathrm{Si}$ wafers. The first sample set was grown with two different thermal $\mathrm{SiO}_{x}$ thicknesses (1.3 and $4 \mathrm{~nm}$ ). They were then coated with various a$\mathrm{Si}: \mathrm{H}$ thicknesses by a plasma-enhanced chemical vapor deposition (PECVD) technique and subjected to a phosphorus diffusion step at different temperatures $\left(780\right.$ and $\left.820^{\circ} \mathrm{C}\right)$. Resultant phosphorus silicate glass (PSG) layers were etched away with a diluted HF solution. The $1.3 \mathrm{~nm} \mathrm{SiO}$ thickness and the diffusion temperatures $\sim 800{ }^{\circ} \mathrm{C}$ were chosen as these parameters and demonstrated to yield a very low recombination current density $\left(4.5-6 \mathrm{fA} / \mathrm{cm}^{2}\right)$ and a reasonably low contact resistivity $\left(0.016-0.07 \Omega \mathrm{cm}^{2}\right) .{ }^{43}$ The second sample set was coated with various $\mathrm{Al}_{2} \mathrm{O}_{3}$ thicknesses $(1$ and $10 \mathrm{~nm}$ ) by an atomic layer deposition (ALD) technique. A-Si:H layers of various thicknesses $(10,20$, and $40 \mathrm{~nm})$ were then deposited onto them by the PECVD technique.

A Horiba LabRam system equipped with confocal optics was employed to perform steady-state PL/Raman spectroscopy measurements. PL spectra were captured with a liquid-nitrogen-cooled InGaAs array detector with a detection range between 750 and $1600 \mathrm{~nm}$. Raman measurements were performed with a chargecoupled-device (CCD) Si array detector whose detection range is between 400 and $1000 \mathrm{~nm}$. Excitation sources for Raman and steadystate PL measurements were single-wavelength solid-state 532 and $405 \mathrm{~nm}$ lasers, respectively. PL excitation spectroscopy was performed with a supercontinuum NKT laser source having a tunable wavelength range between 480 and $2000 \mathrm{~nm}$. Sample temperature was controlled with a THMS600 Linkam stage. The spectral response of the entire system was determined with a calibrated halogen-tungsten light source. 
Time-resolved PL (TRPL) experiments were performed with a picosecond $522 \mathrm{~nm}$ excitation source and a photomultiplier tube (PMT), whose detection range is between 300 and $950 \mathrm{~nm}$. Sample temperature was controlled using a closed-loop liquid-helium-cooled cryostat. Transmission electron microscope (TEM) images were captured using a JEOL JEM-2100F TEM instrument. TEM lamellae were prepared by a focused ion beam (FIB) technique.

\section{RESULTS}

3.1. PL from Doped Poly-Si Films. First, we report PL emission from phosphorus-doped poly-Si layers used for passivating-contact solar cells. Figure la shows PL spectra from an $\mathrm{n}^{+}$poly-Si/1.3 $\mathrm{nm} \mathrm{SiO}_{x} / \mathrm{c}-\mathrm{Si}$ sample at $80 \mathrm{~K}$. The doped poly-Si layer is about $50 \mathrm{~nm}$ thick. The sharp peak located at $\sim 1130 \mathrm{~nm}$ corresponds to the band-to-band emission from the c-Si substrate. ${ }^{44}$ The spectrum measured when a $405 \mathrm{~nm}$ excitation light is used (Figure 1a, dasheddotted blue curve) also contains a very broad peak at wavelengths longer than the emission from the c-Si substrate. With increasing excitation wavelength, the laser light penetrates more deeply into the substrate, and the resulting PL spectrum contains mainly the emission from c-Si (Figure la, dash red curve). Thus, the difference between the two spectra (Figure 1a, continuous black curve) represents the emission from the near-surface layer. Moreover, the intensity of this broad peak increases with increasing thicknesses of the doped poly-Si film (Figure 1b), confirming that it originates from the poly-Si layer.

In order to verify that the original a-Si:H film has been recrystallized after the phosphorus diffusion process, we capture Raman spectra from different samples, one crystalline, another amorphous, and a third polycrystalline, and display them in Figure 1c. The results clearly indicate that in the doped poly-Si sample the initial amorphous phase has partially become a crystalline phase. The deviation between the doped poly-Si and the c-Si Raman spectra (inset in Figure 1c) suggests that some amorphous phase remains in the film, as confirmed by the high-resolution TEM image at the interface (Figure 1d). In fact, the crystalline and amorphous volume fractions in the poly-Si film could be potentially extracted from the Raman spectra by deconvoluting the amorphous and c-Si peaks. ${ }^{45,46}$ However, our Raman experiments were done with the $532 \mathrm{~nm}$ laser (absorption depth $\sim 1.2 \mu \mathrm{m}$ in poly-Si), and thus, a significant fraction of the excitation light also hits the c$\mathrm{Si}$ substrate. Therefore, the c-Si Raman peak in Figure 1d originates from both the poly-Si film and the substrate, making it difficult to extract the crystalline and amorphous volume fractions in the film.

In addition, the fact that the wavelengths of the doped poly$\mathrm{Si} \mathrm{PL}$ emission stretch from the c-Si peak to very long wavelengths (Figure 1a, solid black curve) suggests that this doped poly-Si layer contains radiative defects whose energy levels stretch from the band edges to deep levels inside the doped poly-Si bandgap. If this is the case, the doped poly-Si emission should be quenched significantly with increasing sample temperature, due to the inherent properties of defect luminescence. Figure le shows a strong PL quenching rate with temperature for the doped poly-Si film, confirming our hypothesis. Note that it is not possible to extract activation energies for these sub-bandgap levels from the temperature dependence of the PL curve, as the poly-Si PL peak does not originate from discrete energy levels, as it does in the case of sub-bandgap PL spectra from dislocations and impurities in cSi wafers. ${ }^{47,48}$

Next, employing the luminescence signal from doped poly$\mathrm{Si} / \mathrm{SiO}_{x}$ structures, we investigate free-carrier transport in these layers. Figure $2 \mathrm{a}$ shows the dependence of the intensity of the
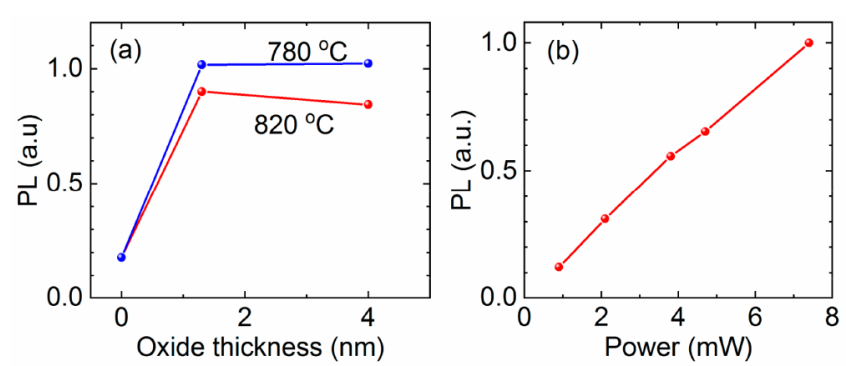

Figure 2. (a) Dependence of integrated poly-Si PL intensity on oxide thickness. Phosphorus diffusion temperatures are 820 and $780^{\circ} \mathrm{C}$. (b) Dependence of integrated poly-Si PL intensity on laser excitation power. $T=80 \mathrm{~K}, \lambda_{\text {exc }}=405 \mathrm{~nm}$.

doped poly-Si PL peak on oxide thicknesses. As can be seen in this figure, both cases of 1.3 and $4 \mathrm{~nm}$ thick oxides yield approximately the same PL intensity. Moreover, Figure $2 \mathrm{~b}$ shows a strong dependency of the poly-Si PL intensity on laser excitation power, which clearly indicates that the poly-Si PL intensity is strongly dependent on the density of excess carriers generated within the film, rather than on being saturated. Therefore, the results in Figure $2 \mathrm{a}$ indicate that the excess carrier density must be similar between the cases of 1.3 and 4 $\mathrm{nm}$ oxides. In other words, very few carriers photogenerated inside the poly-Si film have moved across the $1.3 \mathrm{~nm}$ oxide layer. However, when no oxide layer is present (zero oxide thickness, Figure 2a), the emission from the poly-Si film is reduced drastically.

Let us examine possible underlying mechanisms of the observed reduction of the PL emission from the poly-Si when no intentional oxide layer is present. Without the $\mathrm{SiO}_{x}$ layer, the film may have become fully crystallized upon annealing and its luminescence is undistinguishable from that of the substrate. However, both Raman and TEM results confirm that the film still contains some amorphous $\mathrm{Si}$ phase (Figure 3a,b). Therefore, there is likely a lack of carrier build-up in the film (without the $\mathrm{SiO}_{x}$ layer). This can be due to the direct interface between the film and the substrate, as can be seen in the TEM image in Figure $3 b$, which contain a high defect density and/or a strong carrier injection from the film into the

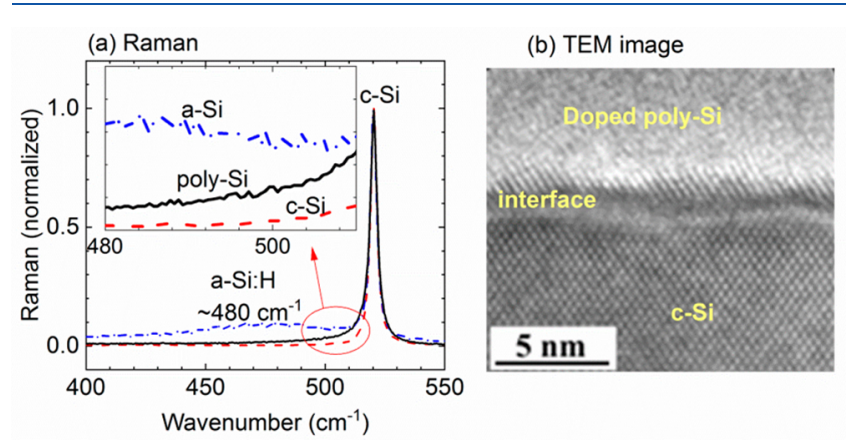

Figure 3. (a) Raman spectra from a-Si:H and doped poly-Si films without an $\mathrm{SiO}_{x}$ interlayer. (b) High-resolution TEM image of the $\mathrm{n}^{+}$ poly/c-Si interface. 
substrate. However, differentiating between the two mechanisms is not possible under our experiments.

3.2. Extension to a-Si:H Films. Recently, several works have reported free-carrier coupling from a-Si:H passivation films with c-Si substrates in heterojunction solar cells. ${ }^{49-51}$ Using internal quantum efficiency (IQE) and ellipsometry measurements, Holman et al. found an electronic coupling of free carriers generated in a-Si:H films with c-Si absorbers, thus adding to the final photocurrent of their $\mathrm{c}$-Si heterojunction cells. ${ }^{49}$ Meanwhile, Paduthol et al. measured spectral responses of PL and compared them with IQEs calculated from absorption losses in a-Si:H to quantify such free-carrier couplings. ${ }^{50,51}$ In this section, applying the same concept mentioned above, we also find direct evidence of the freecarrier coupling despite our very different approach compared to the previous works.

Figure 4 shows typical PL spectra captured from c-Si samples capped with a-Si:H films. The sharp peak located at

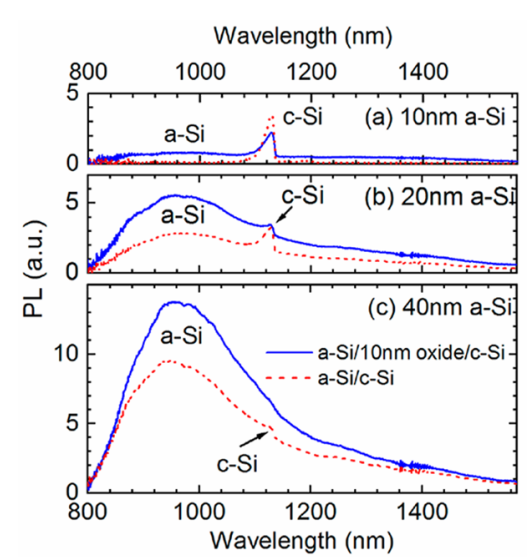

Figure 4. Comparison of $\mathrm{PL}$ spectra of a-Si:H/c-Si and a-Si:H/10 nm $\mathrm{Al}_{2} \mathrm{O}_{3} / \mathrm{c}$-Si samples: (a) $10 \mathrm{~nm}$, (b) $20 \mathrm{~nm}$, and (c) $40 \mathrm{~nm}$ of a-Si:H. $T=80 \mathrm{~K}, \lambda_{\text {exc }}=405 \mathrm{~nm}$.

$\sim 1130 \mathrm{~nm}$ is the band-to-band emission from the c-Si substrate, whereas the very broad peak $\sim 900-1000 \mathrm{~nm}$ is the emission from the a-Si:H film. ${ }^{44}$ The distinct difference between $\mathrm{c}-\mathrm{Si}$ and a-Si:H peaks is due to the different emission mechanisms in both materials. The emission from c-Si originates from the two rigid band edges, and thus, the spectrum is very sharp at low temperatures. Meanwhile, the emission from a-Si:H originates from the two band tails inside the bandgap, and thus, the spectrum is very broad and extends to much smaller energies (i.e., longer wavelengths) than the bandgap of the a-Si:H film itself. ${ }^{52-54}$

In Figure 4a the emission from the a-Si: $\mathrm{H}$ film increases with film thickness and is also stronger when a thin layer of $\mathrm{Al}_{2} \mathrm{O}_{3}$ is inserted between the film and the wafer. In the absence of such an interlayer, the $10 \mathrm{~nm}$ thick a-Si:H/c-Si sample does not show any emission from the a-Si:H film. This suggests that a significant number of excess carriers generated in the film may have moved into the substrate for the a-Si:H/c-Si sample, but they are blocked by a $10 \mathrm{~nm}$ layer of $\mathrm{Al}_{2} \mathrm{O}_{3}$ for the a-Si:H/ $\mathrm{Al}_{2} \mathrm{O}_{3} / \mathrm{c}$-Si sample. As Figure $4 \mathrm{~b}$ indicates, the same conclusion can be obtained for the $20 \mathrm{~nm}$ thick film. Being thicker, the a$\mathrm{Si}: \mathrm{H}$ film produces a stronger emission, even in the absence of an oxide interlayer ( $\mathrm{a}-\mathrm{Si}: \mathrm{H} / \mathrm{c}-\mathrm{Si}$ sample). What is remarkable is that the $\mathrm{c}-\mathrm{Si}$ peak in Figure $4 \mathrm{~b}$ is stronger for the case of no interlayer (red dotted line) compared to the case when an oxide interlayer is present (blue continuous line), confirming that a significant number of excess carriers have been injected to the wafer when no interlayer is present (the smallish c-Si peak in the blue line is due to some light having penetrated through the $20 \mathrm{~nm}$ film). When the film thickness is increased up to $40 \mathrm{~nm}$, the excitation light is mostly absorbed inside the a-Si:H layer. Thus, we hardly detect any PL signal from the c$\mathrm{Si}$ substrate (Figure 4c, solid blue curve) for the a-Si: $\mathrm{H} / \mathrm{Al}_{2} \mathrm{O}_{3} /$ c-Si sample. However, when the $\mathrm{Al}_{2} \mathrm{O}_{3}$ layer is absent, the free carriers still flow into the $\mathrm{c}-\mathrm{Si}$ substrate, giving rise to a small c$\mathrm{Si}$ peak (Figure 4c, broken red curve).

Next, we verify the hypothesis of the free-carrier coupling from the a-Si:H films mentioned above with PL excitation (PLE) and TRPL spectroscopy. Figure 5a shows PL intensities
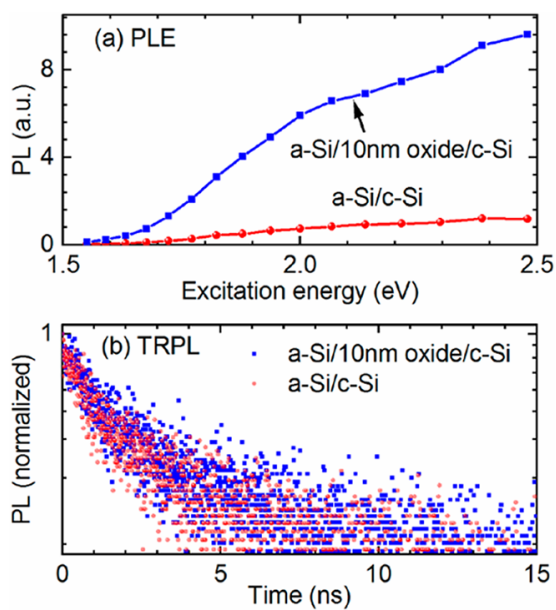

Figure 5. (a) Integrated a-Si:H PL intensities $(800-1050 \mathrm{~nm})$ versus excitation energies. (b) TRPL curves of the a-Si:H PL peak. $T=80 \mathrm{~K}$.

from the a-Si:H films versus excitation energies. We can observe two distinct trends for samples with and without an $\mathrm{Al}_{2} \mathrm{O}_{3}$ layer. At low excitation energies (long wavelength), there is no emission from the a-Si:H films for both samples as the excitation light is not sufficiently absorbed in the films to give PL emissions. However, with increasing excitation energies, the $\mathrm{PL}$ intensity from the sample with the $\mathrm{Al}_{2} \mathrm{O}_{3}$ layer increases much more rapidly than that from the sample without it. This suggests that the increment of free-carrier concentrations inside the a-Si:H films is faster for the a-Si:H/ $\mathrm{Al}_{2} \mathrm{O}_{3} / \mathrm{c}$-Si case than for the a-Si:H/c-Si case. To verify that the faster emission increment is not due to a better a-Si:H film quality, we capture TRPL decay curves of the a-Si:H peak $(\sim 950 \mathrm{~nm})$ and plot them in Figure $5 \mathrm{~b}$. The two curves from a-Si:H/ $\mathrm{Al}_{2} \mathrm{O}_{3} / \mathrm{c}-\mathrm{Si}$ and $\mathrm{a}-\mathrm{Si}: \mathrm{H} / \mathrm{c}-\mathrm{Si}$ samples are almost identical, demonstrating that the $\mathrm{Al}_{2} \mathrm{O}_{3}$ layer does not affect the a-Si:H film quality. Therefore, the much lower steady-state $\mathrm{PL}$ signal of a-Si:H from the sample without the oxide layer must be due to the free carriers moving from the film into the substrate. This observation is consistent with findings reported by authors in refs 49-51 although they conducted experiments at room temperature whereas our study was at $80 \mathrm{~K}$. Different temperatures could lead to different degrees of the free-carrier coupling but should not change the transport mechanism.

Finally, we show that an ultrathin layer of $\mathrm{Al}_{2} \mathrm{O}_{3}(\sim 1 \mathrm{~nm})$ is sufficient to block the transport of the excess carriers from the $\mathrm{a}-\mathrm{Si}: \mathrm{H}$ film into the substrate; i.e., there is no free-carrier coupling from the film. Figure $6 \mathrm{a}$ shows dependencies of a- 

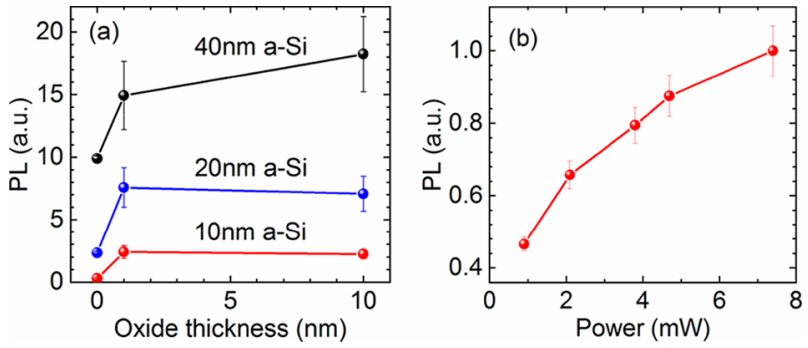

Figure 6. (a) Dependence of integrated a-Si:H PL intensities on $\mathrm{Al}_{2} \mathrm{O}_{3}$ thicknesses. (b) Dependence of integrated a-Si:H PL intensities on excitation powers for the $20 \mathrm{~nm}$ a-Si:H/10 nm Al${ }_{2} \mathrm{O}_{3} / \mathrm{c}$-Si sample. $T=80 \mathrm{~K}, \lambda_{\text {exc }}=405 \mathrm{~nm}$.

$\mathrm{Si}: \mathrm{H} \mathrm{PL}$ intensities on $\mathrm{Al}_{2} \mathrm{O}_{3}$ thicknesses. Consistently across various a-Si:H thicknesses, the $\mathrm{PL}$ intensity is the same for both 10 and $1 \mathrm{~nm}$ oxide thicknesses. Meanwhile, the PL intensity of the sample without the oxide layer (zero thickness) is reduced significantly. These results demonstrate that the 1 $\mathrm{nm}$ layer of oxide can efficiently block the coupling of most photoinduced carriers from the a-Si:H film with the c-Si base. There could be another possibility that the excess carriers still move into the substrate but the a-Si:H PL intensity may not be sensitive to the carrier concentration variation. However, Figure $6 \mathrm{~b}$ shows that this is not the case. There is still a strong dependence of a-Si:H PL intensities on excitation powers and thus carrier concentrations.

\section{CONCLUSION}

We have reported luminescence phenomena from phosphorusdoped polycrystalline silicon and hydrogenated amorphous silicon films and employed them to investigate transport properties of free carriers photogenerated in the films. The doped polycrystalline silicon films were found to emit a strong and broad luminescence peak at low temperatures, stretching from the crystalline silicon peak position to much longer wavelengths. This suggested that the doped polycrystalline silicon layers contained radiative defects whose energy levels stretched from the band edges to deep levels inside the doped polycrystalline silicon bandgap. In addition, the carrier populations photogenerated in both polycrystalline silicon and hydrogenated amorphous silicon films were found to vanish when the films were placed directly on the c-Si substrates. However, with the presence of an ultrathin oxide interlayer, there was a significant carrier build-up in the films, but these carriers could not move into the substrate. This demonstrates that there is no free-carrier coupling in practical passivating-contact solar cells.

\section{AUTHOR INFORMATION}

\section{Corresponding Author}

*E-mail: hieu.nguyen@anu.edu.au.

\section{ORCID $\odot$}

Hieu T. Nguyen: 0000-0003-1667-1135

Anyao Liu: 0000-0003-4579-5495

Thien N. Truong: 0000-0002-4082-7999

Mike Tebyetekerwa: 0000-0002-4243-6043

Ziyuan Li: 0000-0001-9400-6902

\section{Notes}

The authors declare no competing financial interest.

\section{ACKNOWLEDGMENTS}

This work has been supported by the Australian Renewable Energy Agency (ARENA) through Research Grant RND017 and the U.S. Department of Energy under Contract DE-AC3608GO28308 with the National Renewable Energy Laboratory (NREL). The authors acknowledge the facility and technical support support from the Australian National Fabrication Facility (ANFF) ACT Node and the Centre for Advanced Microscopy (CAM) at the ANU. H.T.N. acknowledges the fellowship support from the Australian Centre for Advanced Photovoltaics (ACAP) and the ACAP Collaboration Grant. M.T. acknowledges the support from the Australian Government Research Training Program (RTP) Scholarship.

\section{REFERENCES}

(1) Daub, E.; Würfel, P. Ultralow Values of The Absorption Coefficient of Si Obtained from Luminescence. Phys. Rev. Lett. 1995, $74,1020-1023$.

(2) Daub, E.; Würfel, P. Ultralow Values of The Absorption Coefficient for Band-Band Transitions in Moderately Doped Si Obtained from Luminescence. J. Appl. Phys. 1996, 80, 5325-5331.

(3) Trupke, T.; Green, M. A.; Würfel, P.; Altermatt, P. P.; Wang, A.; Zhao, J.; Corkish, R. Temperature Dependence of The Radiative Recombination Coefficient of Intrinsic Crystalline Silicon. J. Appl. Phys. 2003, 94, 4930-4937.

(4) Nguyen, H. T.; Rougieux, F. E.; Mitchell, B.; Macdonald, D. Temperature Dependence of The Band-Band Absorption Coefficient in Crystalline Silicon from Photoluminescence. J. Appl. Phys. 2014, 115, 043710.

(5) Altermatt, P. P.; Geelhaar, F.; Trupke, T.; Dai, X.; Neisser, A.; Daub, E. Injection Dependence of Spontaneous Radiative Recombination in Crystalline Silicon: Experimental Verification and Theoretical Analysis. Appl. Phys. Lett. 2006, 88, 261901.

(6) Nguyen, H. T.; Baker-Finch, S. C.; Macdonald, D. Temperature Dependence of The Radiative Recombination Coefficient in Crystalline Silicon from Spectral Photoluminescence. Appl. Phys. Lett. 2014, 104, 112105.

(7) Bludau, W.; Onton, A.; Heinke, W. Temperature Dependence of The Band Gap of Silicon. J. Appl. Phys. 1974, 45, 1846-1848.

(8) Wagner, J. Photoluminescence and Excitation Spectroscopy in Heavily Doped n- and p-Type Silicon. Phys. Rev. B: Condens. Matter Mater. Phys. 1984, 29, 2002-2009.

(9) Wagner, J. Band-Gap Narrowing in Heavily Doped Silicon at 20 and $300 \mathrm{~K}$ Studied by Photoluminescence. Phys. Rev. B: Condens. Matter Mater. Phys. 1985, 32, 1323-1325.

(10) Tajima, M. Determination of Boron and Phosphorus Concentration in Silicon by Photoluminescence Analysis. Appl. Phys. Lett. 1978, 32, 719-721.

(11) Liu, A. Y.; Nguyen, H. T.; Macdonald, D. Quantifying Boron and Phosphorous Dopant Concentrations in Silicon from Photoluminescence Spectroscopy at 79 K. Phys. Status Solidi A 2016, 213, 3029-3032.

(12) Würfel, P.; Trupke, T.; Puzzer, T.; Schäffer, E.; Warta, W.; Glunz, S. W. Diffusion Lengths of Silicon Solar Cells from Luminescence Images. J. Appl. Phys. 2007, 101, 123110.

(13) Giesecke, J. A.; Kasemann, M.; Warta, W. Determination of Local Minority Carrier Diffusion Lengths in Crystalline Silicon from Luminescence Images. J. Appl. Phys. 2009, 106, 014907.

(14) Mitchell, B.; Trupke, T.; Weber, J. W.; Nyhus, J. Bulk Minority Carrier Lifetimes and Doping of Silicon Bricks from Photoluminescence Intensity Ratios. J. Appl. Phys. 2011, 109, 08311.

(15) Barugkin, C.; Wan, Y.; Macdonald, D.; Catchpole, K. R. Evaluating Plasmonic Light Trapping with Photoluminescence. IEEE Journal of Photovoltaics 2013, 3, 1292-1297.

(16) Dreckschmidt, F.; Möller, H.-J. Defect Luminescence at Grain Boundaries in Multicrystalline Silicon. Phys. Status Solidi C 2011, 8, $1356-1360$. 
(17) Olsen, E.; Flø, A. S. Spectral and Spatially Resolved Imaging of Photoluminescence in Multicrystalline Silicon Wafers. Appl. Phys. Lett. 2011, 99, 011903.

(18) Tajima, M.; Iwata, Y.; Okayama, F.; Toyota, H.; Onodera, H.; Sekiguchi, T. Deep-Level Photoluminescence Due to Dislocations and Oxygen Precipitates in Multicrystalline Si. J. Appl. Phys. 2012, 111, 113523.

(19) Burud, I.; Flø, A. S.; Olsen, E. On The Origin of Inter Band Gap Radiative Emission in Crystalline Silicon. AIP Adv. 2012, 2, 042135.

(20) Lausch, D.; Mehl, T.; Petter, K.; Flø, A. S.; Burud, I.; Olsen, E. Classification of Crystal Defects in Multicrystalline Silicon Solar Cells and Wafer Using Spectrally and Spatially Resolved Photoluminescence. J. Appl. Phys. 2016, 119, 054501.

(21) Gundel, P.; Schubert, M. C.; Kwapil, W.; Schön, J.; Reiche, M.; Savin, H.; Yli-Koski, M.; Sans, J. A.; Martinez-Criado, G.; Seifert, W.; Warta, W.; Weber, E. R. Micro-Photoluminescence Spectroscopy on Metal Precipitates in Silicon. Phys. Status Solidi RRL 2009, 3, 230232.

(22) Pizzini, S.; Guzzi, M.; Grilli, E.; Borionetti, G. The Photoluminescence Emission in The 0.7-0.9 eV Range from Oxygen Precipitates, Thermal Donors and Dislocations in Silicon. J. Phys.: Condens. Matter 2000, 12, 10131-10143.

(23) Binetti, S.; Pizzini, S.; Leoni, E.; Somaschini, R.; Castaldini, A.; Cavallini, A. Optical Properties of Oxygen Precipitates and Dislocations in Silicon. J. Appl. Phys. 2002, 92, 2437-2445.

(24) Bothe, K.; Falster, R. J.; Murphy, J. D. Room Temperature SubBandgap Photoluminescence from Silicon Containing Oxide Precipitates. Appl. Phys. Lett. 2012, 101, 032107.

(25) Rougieux, F. E.; Nguyen, H. T.; Macdonald, D. H.; Mitchell, B.; Falster, R. Growth of Oxygen Precipitates and Dislocations in Czochralski Silicon. IEEE Journal of Photovoltaics 2017, 7 (3), 735740.

(26) Nguyen, H. T.; Han, Y.; Ernst, M.; Fell, A.; Franklin, E.; Macdonald, D. Dislocations in Laser-Doped Silicon Detected by Micro-Photoluminescence Spectroscopy. Appl. Phys. Lett. 2015, 107, 022101.

(27) Han, Y.-J.; Franklin, E.; Fell, A.; Ernst, M.; Nguyen, H. T.; Macdonald, D. Low-Temperature Micro-Photoluminescence Spectroscopy on Laser-Doped Silicon with Different Surface Conditions. Appl. Phys. A: Mater. Sci. Process. 2016, 122, 420.

(28) Deshpande, S. V.; Gulari, E.; Brown, S. W.; Rand, S. C. Optical Properties of Silicon Nitride Films Deposited by Hot Filament Chemical Vapor Deposition. J. Appl. Phys. 1995, 77, 6534-6541.

(29) Molinari, M.; Rinnert, H.; Vergnat, M. Evolution with The Annealing Treatments of The Photoluminescence Mechanisms in aSiNx:H Alloys Prepared by Reactive Evaporation. J. Appl. Phys. 2007, 101, 123532

(30) Debieu, O.; Nalini, R. P.; Cardin, J.; Portier, X.; Perrière, J.; Gourbilleau, F. Structural and Optical Characterization of Pure Si-rich Nitride Thin Films. Nanoscale Res. Lett. 2013, 8, 31.

(31) Nguyen, H. T.; Johnston, S.; Basnet, R.; Guthrey, H.; Dippo, P.; Zhang, H.; Al-Jassim, M. M.; Macdonald, D. Imaging the Thickness of Passivation Layers for Crystalline Silicon with MicronScale Spatial Resolution Using Spectral Photoluminescence. Solar RRL 2017, 1, 1700157.

(32) Cuevas, A.; Allen, T.; Bullock, J.; Wan, Y.; Yan, D.; Zhang, X. Skin Care for Healthy Silicon Solar Cells. In Proc. 42nd IEEE Photovolt. Spec. Conf.; New Orleans, LA, 2015; pp 1-6.

(33) Battaglia, C.; Cuevas, A.; De Wolf, S. High-Efficiency Crystalline Silicon Solar Cells: Status and Perspectives. Energy Environ. Sci. 2016, 9, 1552-1576.

(34) Melskens, J.; van de Loo, B. W. H.; Macco, B.; Black, L. E.; Smit, S.; Kessels, W. M. M. Passivating Contacts for Crystalline Silicon Solar Cells: From Concepts and Materials to Prospects. IEEE Journal of Photovoltaics 2018, 8, 373-388.

(35) Glunz, S. W.; Feldmann, F. $\mathrm{SiO}_{2}$ Surface Passivation Layers A Key Technology for Silicon Solar Cells. Sol. Energy Mater. Sol. Cells 2018, 185, 260-269.
(36) Schmidt, J.; Peibst, R.; Brendel, R. Surface Passivation of Crystalline Silicon Solar Cells: Present and Future. Sol. Energy Mater. Sol. Cells 2018, 187, 39-54.

(37) Masuko, K.; Shigematsu, M.; Hashiguchi, T.; Fujishima, D.; Kai, M.; Yoshimura, N.; Yamaguchi, T.; Ichihashi, Y.; Mishima, T.; Matsubara, N.; Yamanishi, T.; Takahama, T.; Taguchi, M.; Maruyama, E.; Okamoto, S. Achievement of More Than 25\% Conversion Efficiency with Crystalline Silicon Heterojunction Solar Cell. IEEE Journal of Photovoltaics 2014, 4, 1433-1435.

(38) Nakamura, J.; Asano, N.; Hieda, T.; Okamoto, C.; Katayama, H.; Nakamura, K. Development of Heterojunction Back Contact Si Solar Cells. IEEE Journal of Photovoltaics 2014, 4, 1491-1495.

(39) Yoshikawa, K.; Yoshida, W.; Irie, T.; Kawasaki, H.; Konishi, K.; Ishibashi, H.; Asatani, T.; Adachi, D.; Kanematsu, M.; Uzu, H.; Yamamoto, K. Exceeding Conversion Efficiency of $26 \%$ by Heterojunction Interdigitated Back Contact Solar Cell with Thin Film Si Technology. Sol. Energy Mater. Sol. Cells 2017, 173, 37-42.

(40) Glunz, S. W.; Feldmann, F.; Richter, A.; Bivour, M.; Reichel, C.; Steinkemper, H.; Benick, J.; Hermle, M. The Irresistible Charm of a Simple Current Flow Pattern-25\% with a Solar Cell Featuring a Full-Area Back Contact. In Proc. 31st Eur. Photovolt. Sol. Energy Conf.; Hamburg, Germany, 2015; pp 259-263.

(41) Richter, A.; Benick, J.; Feldmann, F.; Fell, A.; Hermle, M.; Glunz, S. W. n-Type Si Solar Cells with Passivating Electron Contact: Identifying Sources for Efficiency Limitations by Wafer Thickness and Resistivity Variation. Sol. Energy Mater. Sol. Cells 2017, 173, 96-105.

(42) Haase, F.; Kiefer, F.; Schäfer, S.; Kruse, C.; Krügener, J.; Brendel, R.; Peibst, R. Interdigitated Back Contact Solar Cells with Polycrystalline Silicon on Oxide Passivating Contacts for Both Polarities. Jpn. J. Appl. Phys. 2017, 56, 08MB15.

(43) Yan, D.; Cuevas, A.; Bullock, J.; Wan, Y.; Samundsett, C. Phosphorus-Diffused Polysilicon Contacts for Solar Cells. Sol. Energy Mater. Sol. Cells 2015, 142, 75-82.

(44) Nguyen, H. T.; Rougieux, F. E.; Yan, D.; Wan, Y.; Mokkapati, S.; de Nicolas, S. M.; Seif, J. P.; De Wolf, S.; Macdonald, D. Characterizing Amorphous Silicon, Silicon Nitride, and Diffused Layers in Crystalline Silicon Solar Cells using Micro-Photoluminescence Spectroscopy. Sol. Energy Mater. Sol. Cells 2016, 145, 403-411.

(45) Bustarret, E.; Hachicha, M. A.; Brunel, M. Experimental Determination of The Nanocrystalline Volume Fraction in Silicon Thin Films from Raman Spectroscopy. Appl. Phys. Lett. 1988, 52, $1675-1677$

(46) Houben, L.; Luysberg, M.; Hapke, P.; Carius, R.; Finger, F.; Wagner, H. Structural Properties of Microcrystalline Silicon in The Transition from Highly Crystalline to Amorphous Growth. Philos. Mag. A 1998, 77, 1447-1460.

(47) Suezawa, M.; Sasaki, Y.; Sumino, K. Dependence of Photoluminescence on Temperature in Dislocated Silicon Crystals. Physica Status Solidi A 1983, 79, 173-181.

(48) Schubert, M. C.; Gundel, P.; The, M.; Warta, W.; Romero, M.; Ostapenko, S.; Arguirov, T. Spatially Resolved Luminescence Spectroscopy on Multicrystalline Silicon. In Proc. of 23rd EUPVSEC; Valencia, 2008; pp 17-23.

(49) Holman, Z. C.; Descoeudres, A.; Barraud, L.; Fernandez, F. Z.; Seif, J. P.; De Wolf, S.; Ballif, C. Current Losses at the Front of Silicon Heterojunction Solar Cells. IEEE J. Photovoltaics 2012, 2, 7-15.

(50) Paduthol, A.; Juhl, M. K.; Hameiri, Z.; Nogay, G.; Löper, P.; Trupke, T. Efficient Carrier Injection from Amorphous Silicon into Crystalline Silicon Determined from Photoluminescence. In Proc. 33rd Eur. Photovolt. Sol. Energy Conf.; Amsterdam, Netherlands, 2017; pp 238-241.

(51) Paduthol, A.; Juhl, M. K.; Nogay, G.; Löper, P.; Ingenito, A.; Trupke, T. Impact of Different Capping Layers on Carrier Injection Efficiency between Amorphous and Crystalline Silicon Measured using Photoluminescence. Sol. Energy Mater. Sol. Cells 2018, 187, 5560 . 
(52) Austin, I. G.; Nashashibi, T. S.; Searle, T. M.; Le Comber, P. G.; Spear, W. E. Photoluminescence and Lifetime Studies on Plasma Discharge a-Si. J. Non-Cryst. Solids 1979, 32, 373-391.

(53) Fischer, R.; Rehm, W.; Stuke, J.; Voget-Grote, U. Thermalization and Recombination of Excess Carriers in a-Si:H. J. Non-Cryst. Solids 1980, 35-36, 687-692.

(54) Rauscher, S.; Pfleiderer, H.; Bullemer, B. Tail-Tail Luminescence in Amorphous Silicon. Physica Status Solidi A 1983, 78, 623632. 